\title{
Geriatrics and Periodontics: A Review
}

\section{MAYANK JAIN ${ }^{1}$, KESARI SINGH²}

Oral health is an important aspect of general well being and in the elderly population compromised oral care has been considered a major risk factor for various health problems. Hence oral-systemic diseases linkage is a special health concern for this elderly population and high quality of oral health care should be available to all regardless of age or circumstances.

KEYWORDS: Oral care, Periodontitis, Geriatrics, Older population, Dental plaque

\section{INTRODUCTION}

The world's population is in transformation with inescapable move in all societies towards an aging population. Due to increased life expectancy there is increase in aging population which further leads to explosion of the aging population that will continue even in the future. ${ }^{1,2,3}$ An increase in proportion of older adults in rural areas is 3\% larger when compared to urban areas as people in villages use less dental services. In order to improve the quality of life of neglected and socioeconomically deprived population, there is requirement of dental health education with emphasis on preventive measures.

Oral health is an integral part of general health as it's been said that oral cavity is referred to as a gateway of overall health and compromised oral care in the elderly population has been considered a risk factor for various general health problems. ${ }^{4}$ Oral health is a lifetime concept and high quality of oral health care should be available to all regardless of age or circumstances. In the elderly population because of physical and neurological changes, oral hygiene is compromised and oral-systemic diseases linkage became a special health concern.

The tissues that invest and support the teeth are called the periodontium. The most important tissue types forming part of the periodontium are: epithelium, connective tissue, cementum and bone. With age, changes may occur in each of these tissues. $^{5}$

As the ligament and bone resorption is irreversible, accumulated tissue damage of periodontitis is reflected in a prevalence and severity that increases with age. In older adults periodontitis depicts various risk factors, which include microbiological factors, behavioural, medical and social factors. With advancing age various changes have been seen in oral hard and soft tissues as well as in bone, the temporomandibular joint and the oral mucosa. These age changes affecting orofacial structures are of clinical importance as some of these limit the prognosis of treatment. ${ }^{1,5}$

\section{AGE RELATED CHANGES IN PERIODONTIUM EPITHELIUM}

Changes in the oral epithelium relate to a thinning of the epithelium and diminished keratinisation and flattening of the rete peg. With advanced age formation of epithelial cross-ridges are seen in papillae involved. Moreover increased cellular density has been seen in the oral epithelium. The mitotic activity increases with increasing age. ${ }^{6,7}$

Connective tissue: Connective tissue shows a gradual transition with age to a denser, coarsely textured tissue in the higher age groups. There is reduction in cellular elements with increase in age. The rate of maturation of the synthesized collagen changes with age. The periodontal ligament of young individuals is well organized and regularly structured. With increasing age, the fiber and cellular contents decrease and the structure of the ligament becomes more and more irregular. ${ }^{6,8,9}$

Cementum: With age, the cementum increases in width along with greater cemental apposition in the apical region of the tooth. ${ }^{10,11,12}$ Cementum is acellular except at the toot apices and in the furcation areas of multirooted teeth. With increasing age, the process of cementum formation 
becomes essentially acellular, remodeling of cementum does not normally take place, local resorption at the cementum surface followed by cementum opposition is often observed. ${ }^{4,10,11}$

Bone: With increasing age, the periodontal surfaces of the alveolar bone become jagged and less insertion of collagen fibers into the bone. An increase in the number of interstitial lamellae has been found. ${ }^{13}$

Width of periodontal ligament space with age: A few number of teeth are left with increased age that leads to increased forces on the remaining teeth. This could explain an increasing width of the periodontal ligament space with age. It has also been noted that the masticatory forces decrease with age. ${ }^{14,15}$

Aging and the location of the junctional epithelium: In a healthy periodontium, the apical termination of the junctional epithelium is located at the cementoenamel junction, just coronal to the connective tissue fiber attachment. But in case of periodontitis, there is break down of dentogingival fibers and the junctional epithelium migrates apically along the root surface. ${ }^{8,10}$

Physiological versus pathological apical migration of the epithelium: As age advances, a gradual physiological recession of the gingiva occurs concomitantly with an apical migration of the epithelium. The recession of the gingiva is a result of occlusal migration of the teeth compensating for occlusal wear and a stable location of the gingival margin. The degree of recession increases with age. $^{16,17}$

VARIOUS TREATMENT MODALITIES OF PERIODONTAL DISEASE IN OLDER ADULTS ${ }^{18}$ Epidemiological data reveal that the prevalence and severity of chronic periodontal disease increase with age. ${ }^{6}$ This observation has primarily been interpreted as an accumulated effect due to lack of adequate periodontal care. However, longitudinal data showing an increased annual rate of destruction of periodontal bone support in individuals older than 70 years as compared with younger age groups. It has been suggested through various studies that systemic factors and/or general health problems in aging individuals may influence disease progression. ${ }^{8,19}$
Goal behind Periodontal Therapy: Regardless of age, the overall objective of periodontal therapy is to preserve a functional dentition by preventing the progression of periodontal diseases. Periodontal treatment needs may also depend upon the general goals of dental therapy. ${ }^{20}$

Approach to therapy: Independent of the age of the patient, the treatment provided must be beneficial and cause no or minimal harm to the patient. Hence it is very important that the planning of the treatment should be preceded by a careful analysis of factors that may influence the outcome and prognosis of therapy. The re-evaluation performed after cause-related periodontal therapy will determine the need for further treatment. Commonly remaining clinical signs of disease such as periodontal pockets $\geq 6 \mathrm{~mm}$ and bleeding following pocket probing are used as criteria for additional periodontal therapy, such as surgical pocket therapy.

\section{Decision Tree for Periodontal Treatment of Older Adults ${ }^{18}$ : Kindly refer figure 1.}

Surgical periodontal therapy: The main objective of surgical periodontal therapy is to preserve the periodontium in long term manner by easing the plaque removal and plaque control. An additional aim may be the regeneration of periodontal support. Age is not a contraindication to periodontal surgery, and the healing obtained following therapy is not different in older adults as compared with younger individuals.

Supportive periodontal therapy: Supportive periodontal therapy is a significant component in the treatment of the periodontitis patient. Kerry $1995^{20}$ described three therapeutic objectives of supportive periodontal treatment:

1. To prevent the progression and recurrence of periodontal disease among patients who have previously been treated for periodontitis;

2. To reduce the incidence of tooth loss;

3. To increase the probability of recognizing and treating other diseases or conditions found within the oral cavity.

Prognosis: It is generally believed that in patients with the same amount of periodontal disease, the rule holds: the older the patient, the better the prognosis in terms of no recurrence of the 
disease. $^{21,22}$ This belief is based mainly on the reasoning that the resistance to periodontal breakdown must be higher in older individuals, since the process of periodontal destruction takes much less time in younger individuals. In spite of age changes in the periodontal tissues and retarded wound healing, periodontal treatment including surgical elimination of pathologically deepened pockets has a favourable prognosis in old patients since they do not represent individuals who are highly susceptible to periodontal disease. In this respect, it is important to know the level of maintenance of oral hygiene in order to avoid recurrence of periodontal breakdown. ${ }^{23,24}$

\section{CONCLUSION}

Today's day's biggest challenge is dental care needs of these older subjects to our society and its care providers. A compromised general condition is very common among elderly population that may negatively affect the patient's ability to maintain oral health. Moreover in case of response to periodontal treatment; the older adults differ from younger individuals. To manage the health care needs of the elderly, coordination between medical and dental care providers will become necessary to design a careful program for supportive therapy.

\section{REFERENCES}

1. US Bureau of the census: Statistical abstract of the United States: 1996, ed 116, Washington DC, 1996, The Bureau.

2. US Department of Commerce, Bureau of the Census: Census 2000 brief, 2001, http://www.census.gov. [Last accessed on $12^{\text {th }}$ January, 2018]

3. Nadig RR, Usha G, Kumar V, Rao R, Bugalia A. Geriatric restorative care- the need, the demand and the challenges. J Conserv Dent 2011;14(3):208-14.

4. Yeh CK, Katz MS, Saunders MJ. Geriatric Dentistry: Integral Component to Geriatric Patient Care: Taiwan Geriatrics \& Gerontology 2008;3(3):182-92.

5. Persson RE, Persson GR. The elderly at risk for periodontitis and systemic diseases. Dent Clin N Am 2005:49(2):279-92.

6. Van der Velden U. Effect Of Age On The Periodontium. Journal Of Clinical Periodontology 1984;11:281-94.

7. Shklar G. The effects of aging upon oral mucosa. Journal of Investigative Dermatology 1966;47:115-20.
8. Loe H, Karring $\mathrm{T}$. The three-dimensional morphology of the epithelium-connective tissue interlace of the gingiva as related to age and sex. Scandinavian Journal of Dental Research 1972;79: 315-26.

9. Meyer J, Marwah AS, Weinmann JP. Mitotic rate of gingival epithelium in two age groups. Journal of Investigative Dermatologv 1956;27:237-47.

10. Grant D, Bernick S. The periodontium of aging humans, Journal of Periodontology 1972;43:660-7. 11. Levy BM, Dreizen S, Bernick S. Effect of aging on the marmoset periodontium. Journal of Oral Pathology 1972;1:61-5.

12. Gargiulo AW, Grant D. Aging changes in the periodontium. Illinois Dental Journal 1973;42:780-5. 13. Severson JA, Moffet BC, Kokich V, Selipsky H. A histological study of age changes in the adult human periodontal joint (ligament). J Periodontol. 1978 Apr;49(4):189-200.

14. Helkimo F, Carlsson GF, Helkimo M. Bite force and state of dentition. Acta Odontologica Scandinavica 1977;35:297-303.

15. Herring SW. Mastication and maturity. A longitudinal study in pigs. Journal of Dental Research. 1977;56:1377-82.

16. McDonagh AJ. Periodontology with special reference to recession of the gums. Journal of Dental Research 1919;1:423-39.

17. Kronfeld R. Increase in size of the clinical crown of human teeth with advancing age. Journal of the American Dental Association 1936;23:382-92.

18. Wennstrom JL. Treatment of periodontal disease in older adults. Periodontology 2000; 16:106-12.

19. Karkaziz HC, Kossioni AE. Oral health status, treatment needs and demands of an elderly institutionalized population in Athens. Eur J Removable Prosthodontics 1993;1:157-63.

20. Kerry GJ. Supportive periodontal treatment. Periodontol 2000 1995;9:176-85.

21. Goldman HM, Cohen DW. (1973) Periodontal Therapy. 5th ed., p. 351. Saint Fouis: Mosby. 22. Schluger S, Yodelis R, Page RC. (1977) Periodontal Disease. Basic Phenomena, Clinical Management, and Occlusaland Restorative Interrelationships. 1st ed., p. 336. Philadelphia: Lea and Febiger

23. Nyman S, Lindhe J, Rosling B. Periodontal surgery in plaque-infected dentitions. J Clin Periodontol. 1977;4(4):240-9.

24. Van der Velden U. Regeneration of the interdental soft tissues following denudation procedures. Journal of Clinical Periodontology 1982:9(6):455-9. 
Source of support: Nil, Conflict of interest: None declared

Cite this article as:

Jain M, Singh K. Geriatrics and Periodontics: A Review. Int Healthcare Res J 2018;2(1):6-9. doi: 10.26440/IHRJ/02_01/156

\section{AUTHOR AFFILIATIONS:}

1. Senior Lecturer, Department of Oral Medicine and Radiology, JN Kapoor DAV(C) Dental College, Yamuna Nagar

2. MDS (Oral Medicine and Radiology), Consultant Dental Surgeon, Greater Noida

\section{Corresponding Author:}

Dr. Kesari Singh

MDS (Oral Medicine and Radiology)

B-27 Delta 1st, Silver Oak Estate

Greater Noida U.P 201308
For article enquiry/author contact details, e-mail at: manuscriptenquiry.ihrj@gmail.com

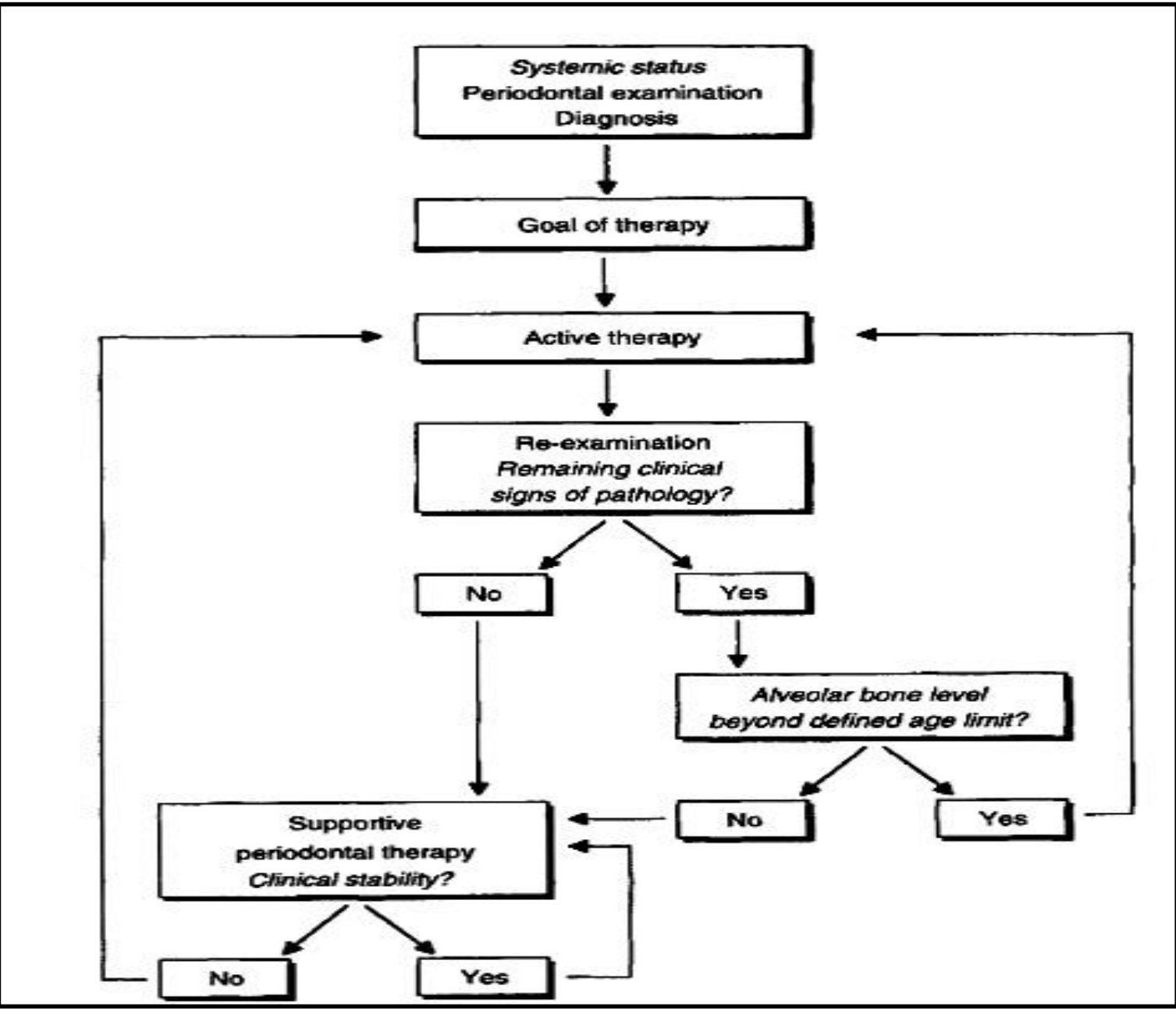

Figure 1. Decision Tree for Periodontal Treatment of Older Adults. ${ }^{18}$ 